\title{
A Conceptual Framework for Teacher Counselors in Colleges
}

\section{OPEN ACCESS}

Manuscript ID:

ASH-2021-09024325

Volume: 9

Issue: 2

Month: October

Year: 2021

P-ISSN: 2321-788X

E-ISSN: 2582-0397

Received: 09.07.2021

Accepted: 31.08 .2021

Published: 01.10.2021

Citation:

Madhavan, Jeena. “A

Conceptual Framework for Teacher Counselors in Colleges." Shanlax International Journal of Arts, Science and Humanities, vol. 9, no. 2, 2021, pp. 157-61.

\section{DOI:}

https://doi.org/10.34293/ sijash.v9i2.4325

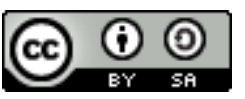

This work is licensed under a Creative Commons Attribution-ShareAlike 4.0 International License

\author{
Jeena Madhavan \\ Assistant Professor, Jain (Deemed to be University), Kochi, Kerala, India \\ https://orcid.org/0000-0002-2264-9658
}

\begin{abstract}
Working with a counsellor helps the student solve a variety of issues that they confront in their daily life, as the sessions in counselling are provided by trained professionals. In the absence of a trained counsellor, a teacher who has received training and practice in the relevant area can play the role of a teacher counsellor. The teacher herself has to undergo a phase of transition from teacher to teacher counsellor. Due to this pandemic situation, life has changed a lot. Researches done in this area shows that the mental health of the adolescent group is largely affected by COVID 19. Even if the present mode of education is online, a teacher counsellor can help a student if she is equipped with the various strategies followed in counselling. The skills which are required in the field of counselling can be achieved by attending courses as well as training programs conducted by universities, government, non-governmental organisations, or institutions. This enables a teacher counsellor to get equipped with the basic skills required for counselling. Also, at the same time, she should be aware of the professional code of ethics in the process of counselling. When the teacher counsellor passes through the transition from teacher to teacher counsellor, she should possess the capacity to understand the student's needs and also be capable of maintaining a good rapport and relationship with the student. In this way, both the teacher counsellor and the student can work together to achieve the goals for change.
\end{abstract}

Keywords: Teacher, Teacher counsellor, Student, Counselling, Counselling skills, Ethics.

\section{Introduction}

In the trajectory of a student's life, the role played by the teacher is not a simple thing. The positive relationship the student build with the teacher makes him more comfortable not only in the academic environment but also in his personal life. During the early years of academic life, the student sees their teacher as their role model, consider them as an affectionate person who always inspires them to do many good things. Thus a good teacher always builds a positive, long-lasting relationship with their students. Constant encouragement and constructive guidance from the teacher's side enable a student to have a strong personal connection with the teacher.

In this pandemic situation, students despite whether at the school level or university level, are facing a lot of psychological issues. Life has changed a lot and during this period for many students, the stressful experiences make them uncomfortable. The most important issue is that they don't know how to deal with the problem. During this situation, the young mind needs guidance and emotional support. Here comes the role of a teacher. A person in the role of a teacher spends most of the time in a classroom setting, helping the students in the process of learning. But there are occasions when the teacher becomes a person who helps the student when the student faces some uncertainties in their life. An effective teacher, apart from teaching, always try to maintain a personal touch with students. Therefore when the teacher plays the role of a counsellor, she should possess the capacity to understand the students' personalities and capability of managing and regulating their emotions. 


\section{Objective}

The paper is an attempt to explore how a teacher can help the adolescent group deal with their problems effectively through the process of counselling. The author attempted to examine and illustrate how a teacher can also play the role of a counsellor, the relevance of teacher counsellors in the educational set up as well as the significance of teacher counsellors in a student's life.

\section{Teacher as a Counselor: Need of the Day}

COVID -19 has made a drastic change in everybody's life. Adolescent groups of students with a lot of energy are now confined into a space where they find it difficult to express their feelings and emotions. The traditional model of classes has now changed to a new model, which has affected the student's overall well-being. Researches done in mental health shows that the pandemic has affected the entire population irrespective of age. A study done in Nepal among health care workers showed that $38 \%$ suffered from anxiety and depression (Gupta et al., 2020). Even before the COVID-19, college students are susceptible to mental health challenges facing unprecedented levels of distress, and early adulthood is one of the peak periods for many mental disorders (De Girolamo et al., 2012). Because counsellors are educators, then counselling is education, and counselling services are educational services (Prayitno, 1998). But counselling services have to be extended not only to the area of education but also importance have to be given emotional level also.

In the present scenario, the best person to help the student from the uncertainties of life is the teacher. When the teacher plays the role of a counsellor, apart from the role of the instructor, they must make some transitions in their dealings and activities with students. Counselling is one form of relationship that is helpful; the counsellor helps the counselee to develop the potential to deal with personal problems, in making decisions and choices in life, and in turn to be productive and happy. Therefore counselling services are directed to assist the development of individuals in school settings and the wider community; it must be organised by professional experts (Mone, 2004).
According to Nkechi (2016) cited that teaching is described as a set of activities that are designed to bring about changes in the behaviour of learners. Popham (2010) sees the role of guidance and counselling as teaching, explaining, demonstrating, guiding, and in this way, the counselling by the teacher help to make a change in the learner. Okoye (2010) stated that the main aim of teaching is to help someone acquire or change some skills, attitude, knowledge, idea or appreciation. In other words, it is to bring about some desirable changes in the learners; she also noted that teaching is said to be effective only when the learners have achieved the set behavioural objectives. Nnabuike (2012) believes that a teacher is also a learner because there is no end to learning.

\section{Transition from Teacher to Counselor}

In the process of teaching, when the teacher identifies a student with behavioural problems, before helping the student, the teacher should go through a transition from the role of a teacher to the role of a counsellor. The transition may not be a very difficult task as the teacher spends a good amount of time with the students. In the class, the teacher is getting the opportunity to observe and orient the student better.

During the process of transition, the teacher has to take up extra responsibilities. In the initial phase, apart from the duties of teaching, the teacher has to consider organising various aspects of students like appointments, maintaining a file which includes tracking progress in the behaviour, communicating with significant family members, etc. have to be taken into consideration. In short, the planning, as well as the organisational skills of the teacher, have to be utilised. In the early phase itself, the teacher should build up an authentic connection with the student. This relationship helps the teacher to gain the trust of the student. In the process of counselling, the teacher's job becomes easier when the teacher is capable of understanding the issues faced by the student in his life. As the teacher is continuously working with the student in the classroom, she is familiar with the common problems faced by the students. The success of counselling doesn't depend on teacher counsellors only. This has to be 
collaborative work that includes family members, principals, teachers, friends, etc., in their roles.

The teacher can become a counsellor on a phase when they become supportive and at the same time while lending an empathetic ear to the student in front of her. The combination of these two qualities makes the teacher more approachable. In the higher education system, even though the government recommends a full-time post for qualified counsellors, this is not implemented in most institutions. Thus in the absence of trained counsellors, teachers who are proficient in dealing with student's issues can bridge this gap. The important aspect is the student who is facing an issue has to be comfortable with the teacher. Empathy, unbiased approach, listening skills, high level of integrity are some of the basic qualities a teacher counsellor should possess. The basic skills regarding counselling can be acquired by attending training programs. The training programs organised by the government as well as non-government helps the teacher to be competent in dealing with student issues which in turn makes the student develop personal, social, and academic competence.

Guidance and counselling services in schools aim to assist the student in fulfilling their basic psychological needs, understanding themselves and developing associations with peers, balancing between permissiveness and controls in the school setting, realising achievement, and providing opportunities to gain independence (Heyden, 2011). The purpose of guidance and counselling, therefore, provides emphasis and strength to educational programs. The specific aims of the counselling program should be understood by the teacher counsellor in a clear way.

Guidance and Counseling service, Ajowi and Simatwa (2010), in their studies noted that Guidance and Counseling services are essential elements in discipline management of people in all societies. The behavioural approach relied on using an external variable to promote acceptable behaviour in school; according to Mutie and Ndambuki (2002), in this approach, teachers manipulate and processes of shaping and extinction to manage the behaviour of students Jones and George (1995). According to Verkey (1993), delinquent children in different parts of the world have confirmed that they are the product of broken or drunken families. Lack of guidance and Counseling to the student may lead to bad peerage. This in turn, may lead to indiscipline in institutions.

\section{Skills Needed for a Teacher Counsellor}

Usually, parents or teachers are the first to notice the behaviour problems in the child. How to handle the crisis becomes a major question in front of them. If the teacher counsellor is not equipped to handle the situation, the case must be directed to a professional level.

The emotional, psychological or social problem faced by the student can be rectified if the teacher counsellor is well prepared to handle the issues. The skills which a teacher should possess in the process of counselling can be achieved through special training and practise so that they will be equipped to handle the issues students face in their life. Thus service counselling should focus directly on the development of the effective life of the student, which is happy with the basic source of individual conceptualisation of counselees, practical directions, and guidance counselling guidelines. The counsellors in academic centres are challenged to be prepared to respond to student clients along to continuum of problems ranging from relatively minor to serious. Depending on the circumstances, they may be able to help with their help. (Locke, Myers, and Herr, 2001)

In an institution, it is not possible to equip all the teachers to become a counsellor. But the management can make aware of the teachers that knowledge about adolescent problems and counselling skills help to improve the student's overall mental health. Therefore if the teacher is equipped with the basic skills of counselling like listening, empathetic attitude, maintaining confidentiality, and integrity, it helps the student to achieve a lot in their personal as well as academic life.

\section{Teacher Counselor and Professional Ethics}

Generally, ethics in our life refers to several variables, which include responsibility, conscience, value, honesty, integrity, principles, etc. They are designed to provide some guidelines for the professional behaviour of members. One of the primary reasons is that "without a code of established ethics, a group of people with similar interests cannot 
be considered a professional organisation" (Allen, 1986).

When the teacher plays the role of a counsellor, it is very challenging, and also, at the same time, she should be able to stick to the professional code of ethics in the process of counselling. During the process, if she can move through the ethical path, she will fulfil one major responsibility to her student. The foremost thing which the teacher counsellor should keep in her mind includes confidentiality, honesty, fairness, patience, and commitment. Thus the code of ethics in teacher counselling can be defined as a set of professional ideas and principles which have to be self-imposed and this should constantly reflect in the contract with the student.

By attending the training sessions, the teacher counsellor will have an awareness regarding how to address the ethical issues in practice. A trusting relationship with the student can be developed by building confidentiality in the communication and discussion, which are the crucial elements in the counselling process. Trust and confidentiality should reflect in the process of communication with parents, teachers, and authorities of the institution. Maintaining a relationship boundary with the student, which can be called a professional distance, is also an important aspect of teacher counselling. Due to individual differences, the problem the students encounter, how they approach the issue, how it affects their social, personal, and emotional life may also differ. Some students need greater attention and others do not know that much. A teacher counsellor should possess the capacity to understand the student's needs and be capable of giving service to all students concerning their needs. Therefore just like any other profession in the area of teacher counselling also maintaining professional, ethical standards helps to promote stability within the profession. Rather than a set of techniques, counselling is a relationship process (James, Stevic and Warner, 1977)

\section{Training for a Teacher Counselor}

When the teacher plays the role of a counsellor, practical knowledge in the field is very important. Adequate knowledge in counselling, the theories, their applications, the issues, research methods are essential factors. A Diploma in counselling should be at a minimum level. Counsellors need to possess a master's degree in psychology to practice. The courses offered in the respective field include theoretical study and practical experience. The skills required for a teacher to practice as a counsellor can be achieved by attending relevant courses in the field. The open universities have started in India, intending to provide equal opportunities to people worldwide to develop their skills and education in the relevant field and to retrain for a new career.

\section{Conclusion}

The services given by the trained teacher counsellor help the student to make significant positive changes in their personal life. By knowing each other, the teacher, counsellor, and the student can develop a therapeutic relationship. This relationship helps the student to make psychological, emotional, and intellectual development. Through the process of counselling, the teacher counsellor encourages the student to make use of available resources and helps in adopting strategies of decision making and problem-solving. In this way, the student, along with the teacher counselor, can navigate the issues in front of them and the teacher provides the tools and insight to manage the tough situations which they face in life. Ultimately, through counseling, the teacher counsellor empowers the student to lead a healthy, fulfilling, and meaningful life.

\section{References}

Agarwal, A.K. "A Review of Indian Psychiatry Research and Ethics." Indian Journal of Psychiatry, vol. 52, 2010, pp. 297-305.

Ajowi, Jack O., and Enose M.W. Simatwa. "The Role of Guidance and Counseling in Promoting Student Discipline in Secondary Schools in Kenya: A Case Study of Kisumu District." Educational Research and Reviews, vol. 5, no. 5, 2010, pp. 263-272.

Allen, Thomas J., and Ralph Katz. "The Dual Ladder: Motivational Solution or Managerial Delusion?." R\&D Management, vol. 16, no. 2, 1986, pp. 185-197.

Areán, Patricia A., and Jennifer Alvidrez. "Ethical Considerations in Psychotherapy 
Effectiveness Research: Choosing the Comparison Group." Ethics \& Behavior, vol. 12, no. 1, 2002, pp. 63-73.

Bond, Tim. "Ethical Guidelines for Researching Counselling and Psychotherapy." Counselling and Psychotheraphy Research, vol. 4, no. 2, 2004, pp. 10-19.

Borders, L. Dianne, and Sandra M. Drury. "Comprehensive School Counseling Programs: A Review for Policymakers and Practitioners." Journal of Counseling \& Development, vol. 70, 1992, pp. 487-498.

De Girolamo, Giovanni, et al. "Age of Onset of Mental Disorders and Use of Mental Health Services: Needs, Opportunities and Obstacles." Epidemiology and Psychiatric Sciences, vol. 21, no. 1, 2012, pp. 47-57.

Etherington, Kim. "The Counsellor as Researcher: Boundary Issues and Critical Dilemmas." British Journal of Guidance and Counselling, vol. 24, no. 3, 1996, pp. 339-346.

Gerler, Edwin R. "Elementary School Counseling Research and the Classroom Learning Environment." Elementary School Guidance \&Counseling, vol. 20, no. 1, 1985, pp. 39-48.

Gupta, A.K., et al. "Psycho-behavioural Impact of 'Lockdown' due to COVID-19 Pandemic in Nepal: An Online Survey." Journal of Psychiatrists' Association of Nepal, vol. 9, no. 1, 2020, pp. 10-15.

Hansen, James C., et al. Counseling: Theory and process. Allyn \& Bacon, 1982.

Locke, Don Cary, et al. The Handbook of Counseling. Sage, 2001.
London, Manuel, et al. "Performance Management and Assessment: Methods for Improved Rater Accuracy and Employee Goal Setting." Human Resource Management, vol. 43, no. 4, 2004, pp. 319-336.

Maruti, et al. "Basic Skill of Counseling Modules to Increase Competence in Professional School Counsellor." International Conference on Education, Science and Training: Empowering Educational Human Resources for Global Competitiveness, 2019, pp. 88-104.

Nkechi, Ebizie Elizabeth, et al. "The Role of Guidance and Counselling in Effective Teaching and Learning in Schools." RAY: International Journal of Multidisciplinary Studies, vol. 1, no. 2, 2016, pp. 36-48.

Nnabuike, E.K. Practical Guide to Effective Teaching. Hallmark Publishers, 2012.

Okoye, A.U. Counselling in the Industrial Setting Visa Vis Industrial Relation. Erudite Publishers, 2010.

Popham, W. James. Everything School Leaders Need to Know about Assessment. Corwin Press, 2010.

Spielberger, Charles D., and Henry Weitz. "Improving the Academic Performance of Anxious College Freshmen: A GroupCounseling Approach to the Prevention of under Achievement." Psychological Monographs: General and Applied, vol. 78, no. $13,1964$.

Varkey, C.P. Handle with Care: You can make or Break your Child. Better Yourself Books, 1993.

Author Details

Jeena Madhavan, Assistant Professor, Jain (Deemed to be University), Kochi, Kerala, India

Email ID: m.jeena@jainuniversity.ac.in. 